\title{
Review
}

\section{Honey bee primer pheromones and colony organization: gaps in our knowledge}

\author{
Mark L. Winston ${ }^{\mathrm{a} *}$, Keith N. Slessor ${ }^{\mathrm{b}}$ \\ aDepartment of Biological Sciences, Simon Fraser University, Burnaby, BC V5A 1S6, Canada \\ ${ }^{b}$ Department of Chemistry, Simon Fraser University, Burnaby, BC V5A 1S6, Canada
}

(Received 21 November 1996; accepted 20 May 1997)

\begin{abstract}
The purpose of this article is to discuss gaps in our knowledge concerning how honey bee primer pheromones mediate worker activities and colony functions. We first review the chemical structure and functions of queen mandibular pheromone (QMP), but then focus primarily on areas of potential future research interest. We discuss the mode of action that QMP may have on workers, address the issue of why QMP is a complex blend of five components, propose an evolutionary pathway for pheromone complexity in the genus Apis, discuss biochemical differences between worker and queen mandibular glands, review the evidence for additional queen pheromones besides QMP, examine how queen and brood pheromones interact to mediate colony biology, and discuss the relative importance of congestion and population size in pheromone transmission. Finally, we suggest some research areas that involve commercial applications of honey bee pheromones for beekeeping and crop pollination. $\mathcal{C}$ Inra/DIB/AGIB/Elsevier, Paris
\end{abstract}

Apis mellifera / primer pheromones / queen pheromones / colony integration

\section{INTRODUCTION}

The purpose of this article is to discuss gaps in our knowledge concerning how honey bee primer pheromones mediate worker activities and colony functions. There is, of course, a great deal known about pheromones in social insects, and especially the honey bee (Free, 1987; Winston, 1987, 1992). However, most of our knowledge about social insect pheromones involves releaser compounds that elicit specific behaviors such as alarm, orientation, trail marking, mate attraction and others. In contrast, we know very little about primer pheromones that exercise a more fundamental level of control by influencing worker physiology, thereby mediating worker and colony reproduction and influencing broad aspects of colony organization, caste structure and division of labour.

\footnotetext{
* Correspondence and reprints

Tel.: (1) 604291 4459; fax: (1) 604291 3496; e-mail: winston@sfu.ca
} 
The honey bee is the only social insect for which any primer pheromone has been identified chemically, and that is the queen's mandibular gland pheromone (QMP). The identities of some pheromone components from the queen's mandibular glands have been known for over 35 years, and were among the first insect pheromones to be identified (Barbier and Lederer, 1960; Callow and Johnston, 1960; Butler and Fairey, 1964; Callow et al., 1964). However, in 1988 additional compounds were reported that, in combination with previously identified components, provide a full duplication of the queen's pheromonal activity from the mandibular gland secretions (Slessor et al., 1988). Additional activity originating from pheromones secreted by other queen glands has yet to be chemically identified (Slessor et al., 1997).

The queen's mandibular gland pheromone, or QMP, consists of five components, including (E)-9-keto-2-decenoic acid (9ODA), (R,E)-(-)- and (S,E)-(+)-9hydroxy-2-decenoic acid (9HDA), methyl $p$-hydroxybenzoate (HOB), and 4hydroxy-3-methoxyphenylethanol (also called homovanillyl alcohol or HVA). This blend may vary in the proportions of individual compounds (Slessor et al., 1990; Pankiw et al., 1996), but all five components are necessary to elicit the full range of worker responses to QMP (Winston et al., 1989, 1990, 1991). Functions of QMP identified to date include the inhibition of queen rearing by workers (Winston and Taylor, 1980; Winston et al., 1989, 1990; Naumann et al., 1993; Pettis et al., 1995a; Melathopolous et al., 1996), attraction of workers to form a retinue around the queen within colonies as well as externally to form a swarm cluster (Winston et al., 1982, 1989; Slessor et al., 1988; Kaminski et al., 1990), stimulation of pollen foraging and brood rearing in small, newly founded colonies (Higo et al., 1992), and delay of worker behavioral transitions from within-hive to foraging tasks (Pankiw et al., 1998). Early studies also reported that QMP inhibits worker ovaries from developing, but subsequent research has suggested that QMP alone has no role in the suppression of worker ovary development and egg laying (Willis et al., 1990; Kaatz et al., 1992a; Plettner et al., 1993). Rather, brood-produced primer pheromones appear to provide the most significani inhibition preventing worker ovary development, in combination with non-mandibular queen pheromones (Jay, 1970, 1972). Brood pheromones also are involved in stimulating cell capping by adult workers (LeConte et al., 1990), and promoting larval feeding and development of adult glands that produce brood food (LeConte, 1995; Mohammedi et al., 1996), although the substances involved are probably different from those that inhibit worker ovary development.

Although there has been extensive basic research concerning queen pheromones for almost 4 decades, and some research investigating potential functions of brood primer pheromones, there still are significant discontinuities in our knowledge concerning these semiochemicals. Yet, we seem to have become complacent concerning our understanding of honey bee sociochemistry. Today, very little research is being conducted worldwide on honey bee or other social insect pheromones. Perhaps we assume that only minor, fine-tuning research remains to be undertaken in this area.

On the contrary, some of the most exciting challenges in insect semiochemistry remain unanswered for any social insect, and our knowledge base concerning honey bees provides an excellent starting point to address these questions. For example, we know that QMP inhibits queen rearing, but to date we can only speculate as to the neurochemical and/or hormonal mechanisms that mediate between pheromone and function. We have dis- 
covered that QMP is a complex blend, but have yet to understand why there are so many components, which worker activities are influenced by which components, why such a complex blend evolved in the first place, and whether workers produce other primer pheromones in their mandibular glands. We have determined that the queen produces additional, non-mandibular pheromones, but have little idea as to their function, origin or identity. We have been aware for some time that brood produces pheromones involved in the inhibition of worker ovary development, but the interactions between brood and queen pheromones for this and other functions, as well as the identities of the relevant brood pheromones, have yet to be determined. We know that pheromone dispersal is slowed in crowded, congested colonies, but have not yet discovered how the queen's message is diluted so that queen rearing can begin prior to swarming. Finally, we have only just begun to explore the potential applications of pheromones for management purposes.

In the following discussion, we will address these and related points, suggesting areas for future research and problems with our current understanding of honey bee pheromone biology.

\section{HOW DOES QMP ACT ON WORKERS AND QUEENS?}

There is a wealth of knowledge available today concerning behaviours elicited by insect pheromones, but very little is known about how pheromones act on insects to induce particular behaviours. This is especially true for social insects, where pheromones such as QMP are involved in a complex array of individual behaviours and colony-level functions.

One important issue for queen mandibular pheromone is to determine how it acts on worker bees to delay for- aging and inhibit queen rearing. An advance in this area was made recently by Pankiw et al. (1998), who demonstrated that the presence of the queen and her QMP message slows the ontogeny from hive tasks to foraging that is typical of worker bee temporal caste ontogeny, by inhibiting the shift from within-nest work to foraging tasks. In these experiments, the addition of synthetic QMP to colonies caused workers to forage at later ages than workers from untreated colonies. In addition, the Pankiw study found that juvenile hormone $(\mathrm{JH})$ titres were lower in workers from QMP-treated colonies, consistent with results from cage experiments by Kaatz et al. (1992a) in which JH levels were suppressed in QMP-treated workers. Since an increase in $\mathrm{JH}$ titre normally is associated with the change from hive to field tasks (Robinson, 1992), these results suggest that QMP may act by inhibiting juvenile hormone production to regulate the rate at which workers progress from within-nest to outside tasks.

This result is exciting because it is the first demonstration of a pheromone-hormonal interaction for honey bees. However, the implications of this finding for the integration of colony functions are not clear. A modulator such as QMP might promote a labor schedule that increases efficiency in task performance by physiologically delaying a shift to the next age caste. The presence of the queen-based inhibitor may be adaptive in preventing all of a colony's young workers from developing too rapidly towards foraging tasks in the event of a sudden loss of older workers due to predation, rapid weather changes or other factors, detaining some for within-hive tasks. Conversely, sudden queen loss could result in increased $\mathrm{JH}$ titres and a corresponding decrease in foraging ages. These possibilities need to be rigorously tested through colony manipulations that adjust temporal caste structure, comparing manipulated colonies in 
the presence and absence of both the queen and synthetic QMP.

The juvenile hormone system also might be involved in solving a paradox in QMP biology: what effect does QMP have on queens themselves? This issue is interesting because queens re-absorb $36 \%$ of their own daily QMP secretion, likely across their cuticles, but also are permanently covered externally with QMP at fairly high concentrations, about $1 \times 10^{-3}$ of their gland contents at any one time (Naumann et al., 1991).

Queens could simply catabolize or ignore their own QMP message, but the experiments demonstrating QMP inhibition of JH in workers (Kaatz et al., 1992a; Pankiw et al., 1998) suggest that QMP also could act on adult queens to suppress their own JH production. This possibility is intriguing because adult honey bee queens are unusual among female egglaying insects in having low levels of $\mathrm{JH}$, except for the first 1-2 days following adult emergence, and $\mathrm{JH}$ apparently is not important in maintaining egg-laying (Fluri et al., 1981; Robinson et al., 1992; Fahrbach et al., 1995). The pattern of high $\mathrm{JH}$ production for the first 2 days of a queen's life, followed by low levels thereafter, is closely and inversely related to the QMP production profile of queens, in which QMP is low upon emergence but rises rapidly during the first 2 days postemergence, and usually stays high for the rest of the queen's life (Slessor et al., 1990; Pankiw et al., 1996). Of course, this relationship between QMP and JH production could be entirely coincidental, but appears worthy of investigation to determine whether the queen mediates both her own and workers' JH production through QMP. If so, QMP may transcend the boundary between pheromone and hormone, which would be of considerable importance in understanding the evolution and function of social insect semiochemicals.
Another significant function of QMP is the inhibition of queen rearing by adult worker honey bees. Workers usually will not rear new queens in the presence of their colony's adult queen, but removal of the queen and her pheromonal message deletes the inhibition by QMP and leads to the rearing of new queens within $12-24 \mathrm{~h}$ (Winston et al., 1989, 1990; Pettis et al., 1995a; Melathopolous et al., 1996). Workers do rear new queens in the presence of the old queen prior to reproductive swarming, probably because pheromone dispersal is reduced in crowded colonies so that her inhibition is insufficient to suppress the queen rearing that precedes swarming (Winston and Taylor, 1980; Winston, 1987; Winston et al., 1991; Naumann et a1., 1993).

The physiological mechanism of QMP's inhibition of queen rearing is completely unknown, but a useful approach to address this issue might exploit genetic differences in worker responses to queen pheromone. Some worker lines are highly responsive and others respond poorly or not at all to QMP in laboratory bioassays (Kaminski et al., 1990; Pankiw et al., 1994, 1995, 1996, 1998). Interestingly, the high responding workers are considerably more likely to be involved in queen rearing than the low responders, for reasons we do not yet understand (Pankiw, 1997). However, there may be physiological differences between high and low responding workers in receiving or responding to the queen's pheromonal message. If so, these differences could provide a powerful tool to dissect the neurochemical and/or hormonal pathways by which QMP prevents workers from performing behaviours or secreting the specialized food associated with queen rearing. We have been conducting some experiments investigating the possibility that brain biogenic amines might mediate these worker activities, but results to date have been inconclusive. A thorough sur- 
vey of brain and hormonal functions in workers rearing and not rearing queens is needed to more fully explore this important topic.

\section{QMP COMPLEXITY AND BIOSYNTHESIS}

Another key issue for honey bee primer pheromone biology is why QMP is such a complex blend. Functionally, we know that all five components move through the colony as a unit, at the same rate (Naumann et al., 1993), and all five are necessary to elicit full retinue response and to suppress queen rearing (Slessor et al., 1988; Winston et al., 1989). However, it is not clear whether all five compounds are physiologically active or whether some components are important only as attractants. We know that there are specific antennal receptors for 9ODA (Allan et al., 1987), and that workers whose antennae have been removed do not respond to QMP in laboratory bioassays (L-A Kaminski, unpublished observations). Also, 9ODA alone is sufficient to inhibit juvenile hormone secretion in worker bees, and there were no differences in JH levels between workers exposed to 9ODA alone and those treated with the full, five-component QMP blend (Kaatz et al., 1992a, unpublished observations). This study suggests that 9ODA may be the physiologically active ingredient that inhibits foraging ontogeny while the other compounds may be important in enhancing worker attraction to the queen or in eliciting worker-worker pheromone transfers. Research concerning neurophysiological responses to, and the physiological effects of, separate and combined components is necessary to confirm this hypothesis.

At an evolutionary level, it is not clear why Apis mellifera has five components to its QMP blend. This condition seems to be derived, since other species of Apis have fewer components and show less differentiation between queen and worker mandibular blends. For example, mandibular glands of queens from the more primitive (Smith, 1991) open-nesting species $A$. dorsata, A. florea and A. andreniformis contain only the three acid components 9ODA and +/- 9HDA, and lack the aromatic HOB and HVA compounds. A. cerana, the other cavity-nesting species besides A. mellifera, has four of the five components but lacks HVA. In addition, mandibular gland secretions from opennesting species show less differentiation between worker and queens bees, and virgin queens from $A$. mellifera show the most profound differences from mated queens of all Apis species (Plettner et al., 1997).

These results provide powerful evidence indicating the evolution towards more complex blends and more pronounced worker-queen differences in honey bee pheromonal systems. However, the implications of this finding for understanding the evolution of highly social behaviour will not be fully appreciated until we have more information concerning pheromonal activity of QMP in other Apis species. Basic comparative studies concerning how single and multiple pheromonal components influence queen rearing, foraging and retinue behaviour in the genus Apis would provide key information to interpret how pheromonal integration of worker and colony functions may have evolved in honey bees, and perhaps in all social insects.

Biosynthetic studies of worker and queen mandibular gland compounds in $A$. mellifera and the other Apis species also might enhance our understanding of the evolution of queen and worker castes. Queen and worker bees of $A$. mellifera each produce a caste-specific blend of functionalized 8 and 10 carbon fatty acids in their mandibular glands, and the biological functions of these compounds 
match the queen's reproductive and worker's non-reproductive roles in the colony. The biosynthetic pathways of these substances result in caste-specific mandibular gland blends, and are particularly important in determining the pheromonal nature of the queen's acidic components (Plettner et al., 1996). Comparative research on the biosynthesis of acidic compounds in queens and workers of other Apis species might reveal significant information relevant to understanding the evolution and structure of caste dimorphism in social insects.

Similarly, biosynthetic studies of the aromatic compounds HOB and HVA might yield important findings concerning the evolution and function of these substances in the genus Apis. Studies involving HVA might be especially significant because of the chemical similarity of HVA to the brain neurochemical dopamine. The biosynthetic relationship between HVA and dopamine is interesting because one functions as a pheromone and the other as a neuromodulator. It is tempting to speculate on how a biosynthetic pathway leading to a neurochemical such as dopamine might have been modified in A. mellifera to produce the pheromone HVA, and also whether HVA and dopamine have similar effects on brain functions. Obviously, this research area is of potential significance to understanding pheromone evolution and pheromoneneurochemical interactions.

Another area of research interest concerns the control mechanisms that determine whether an adult female honey bee will produce queen or worker compounds in her mandibular glands. All Apis species retain the ability in workers and queens to synthesize the acidic mandibular compounds of the other caste. Even A. mellifera workers will produce queen compounds under some circumstances, particularly if they are queenless, and queens similarly retain the capability to synthesize worker substances (Sasaki et al., 1989; Plettner et al., 1993, 1996, 1997). The mechanisms controlling caste-specific biosynthesis are not known, nor do we understand how a worker or queen bee would switch to produce the mandibular blends characteristic of the other caste.

In addition, the functions of the workerproduced acidic components have never been clearly determined. The most abundant compound in worker mandibular glands is 10-hydroxy decenoic acid (10HDA), and it is commonly believed that the functions of this substance are nutritional, as a component of brood food, and medicinal, as an antibiotic (Winston, 1987). However, 10-HDA is most abundant in older workers of foraging age (Plettner et al., 1997), suggesting a foragingrelated function, possibly as a primer pheromone involved in regulating the ages at which workers begin to forage (Huang and Robinson, 1992; Pankiw et al., 1998). If so, 10-HDA and/or other worker-produced mandibular compounds could be the first primer pheromones recognized from honey bee workers. Clearly, the nature and function of worker mandibular compounds that are chemically closely related to queen substances is a research area deserving considerable attention.

All of these investigations would provide information useful to resolve the issue of whether queens control worker activities or workers cooperate in pheromonal transfer and activity. The control hypothesis proposes that the evolution of multicomponent queen pheromone has been an 'arms race' in which the queen has evolved new components to increase her control over worker activities (Winston and Slessor, 1992). In contrast, it may be in the workers' interests to cooperate with the queen in pheromone transfer even though that cooperation results in preventing their own reproduction (Keller and Nonacs, 1993). Data to date are not sufficient or relevant to resolve this issue, 
but an increased understanding of pheromonal evolution might prove especially useful in this context.

\section{OTHER QUEEN PHEROMONES}

It is evident that there are other queenproduced pheromones in addition to QMP, but their glandular sources, chemical identities and functions remain obscure. The existence of other pheromones can be deduced from the gap between the effectiveness of synthetic QMP and that of the queen in effecting worker behaviours (Winston et al., 1989; Winston and Slessor, 1992; Slessor et al., 1997). However, synthetic QMP is identical in activity to extracts from queen mandibular glands, indicating that there are no additional pheromonal substances in these queen glands and that the sources of the queen's additional pheromonal activity lie elsewhere (Slessor et al., 1988, 1997). Various sources for pheromonal queen substances have been proposed, including tergite, tarsal and Dufour's glands.

The queen's tergite glands have long been considered potential pheromonal sources [reviewed by Slessor et al. (1997)]. Proposed functions for these glandular secretions have included attracting drones or workers to the queen in concert with QMP (Gary, 1961; Vierling and Renner, 1977; Smith et al., 1993), recognizing kin (Moritz and Crewe, 1988, 1991), and other primer pheromone functions (Renner and Baumann, 1964; Velthuis, 1967, 1970). Virgin and young queen tergite glands contain considerable quantities of decanoate esters, especially decyl decanoate, that have been isolated and identified from the gland (Espelie et al., 1990), but their activity has not been tested for specific functions. In addition, the tergite glands do not appear to be responsible for attracting workers to their queen (Slessor et al., 1997). Thus, the functions of tergite secretions remain speculative, and the link between identified compounds and functions is as-yet unknown.

Queens also deposit substances on comb that may inhibit queen cell construction, possibly originating from tarsal glands of mated queens (Lensky and Slabezki, 1981). These so-called footprint pheromones could be QMP, since queen mandibular pheromone is deposited by queens as they walk on comb in quantities that could suppress queen rearing (Naumann et al., 1991). Nevertheless, research has not yet ruled out the potential existence of tarsal gland footprint pheromone, and if it does exist the functions of its active ingredients remain unexplored.

A third queen pheromone appears to be produced in the Dufour's gland, and is deposited on eggs as they are laid by the queen (Ratnieks, 1995). The proposed function of this secretion is to identify eggs as queen-laid so that they are not consumed by adult worker bees, as workerlaid eggs frequently are. Again, however, the glandular source, chemical identity and functional activity of this pheromone need to be confirmed and further examined.

Perhaps the most interesting of the unknown queen pheromones originates in the head, in a non-mandibular source. Extracts from queen heads provide almost twice the attractiveness to workers than QMP alone, and recent research has demonstrated that this additional attraction is not due to mandibular gland components, either known or unidentified (Slessor et al., 1997). We are currently working to identify the compound(s) and glandular source of this secretion, but as for the other proposed queen substances its identity, source and function remain speculative. Clearly, there are significant advances yet to be made in identifying other queen honey bee pheromones, let alone for other social insects. 
A more fundamental issue concerns why the queen might need to produce another pheromone. One possibility is that an unidentified queen pheromone, especially from the head, might be important in attracting workers to attend the queen. QMP is removed from queens by worker bees who attend her in a dynamic retinue, licking and antennating the queen to obtain pheromone from her body. The retinue bees attend the queen for seconds to a few minutes, then disperse through the colony as messengers that transmit her chemical message to other workers through antennal and mouthpart contacts over a period of 15 to 30 min (Seeley, 1979; Naumann, 1991; Naumann et al., 1991, 1992; Watmough, 1996). In addition, the queen and messenger bees deposit a relatively minor amount of pheromone on the comb as they walk through the nest, which may then be picked up by other workers walking on the pheromone-impregnated comb (Naumann et al., 1991).

Our initial findings suggested that QMP was the retinue attractant, but subsequently we discovered the existence of lowresponding lines of worker bees that exhibited virtually no response to QMP in laboratory bioassays (Kaminski et al., 1990; Pankiw et al., 1994, 1995). Oddly, workers that have no response to QMP will nevertheless form normal-appearing retinues around the queen, and their colonies show no apparent differences from colonies made up of high-responding workers (Pankiw et al., 1995). These observations suggest that, although QMP clearly is attractive to worker bees, it may be of secondary importance in retinue formation compared to an unidentified queen pheromone.

\section{QUEEN AND BROOD PHEROMONE INTERACTIONS}

Another possible function of unidentified queen pheromones is the suppression of worker ovary development. This area of pheromone biology has been seriously under-studied, and is of unusual significance because it appears to involve the interaction between queen pheromones and brood-produced substances. There is strong evidence indicating that brood produces the primary signal that inhibits worker ovary development, with a queen pheromone providing a secondary signal, but this pheromonal concert remains unexplored. In addition, brood appears to produce a secondary signal inhibiting queen rearing, but the chemical nature and biological function of this putative pheromone is obscure.

The influence of brood in preventing worker ovary development was first described by Jay $(1970,1972)$ in a series of elegant experiments that remain the benchmark in this field. His work involved presenting colonies with various combinations of extracts from queens and brood. The results demonstrated that both brood and the queen were necessary to inhibit ovary development in adult worker bees, and that this effect had a pheromonal basis. In addition, Jay found that the brood signal alone provided a stronger inhibitory effect than the queen pheromone. Subsequent research (Willis et al., 1990; Kaatz et al., 1992b) added the surprising finding that QMP was not the queen pheromone that prevented worker egg laying. Virtually no other progress has been made in identifying the brood pheromone or in further exploring the interaction between queen and brood substances.

However, there have been some tantalizing reports that suggest further exploration of the mechanisms involved in worker ovary inhibition might reveal a complex pheromonal control system with profound implications for our understanding of social insect colony organization. Ovary development in insects involves two processes, the production of yolk proteins (vitellogenin) and ovary 
development and egg production itself. It appears that these two processes may be mediated by different pheromonal systems in the honey bee. Preliminary work suggests that queens may have an important function in suppressing the synthesis of vitellogenin, possibly due to QMP activity (Kaatz et al., 1992b), while brood is likely to be more significant in suppressing ovary development and egg laying in workers (RW Currie, unpublished observations). Further work in this area will provide important information addressing two of the key issues in social insect biology, the proximate nature of the signals mediating reproductive differences between queens and workers and the ultimate pathways by which colony structure evolved.

A second interaction between queen and brood pheromones involves the inhibition of queen rearing. Surprisingly, there is an inverse relationship between the number of queens reared and the quantity of young brood provided to workers in queenless colonies (Pettis et al., 1997). This result was unexpected because workers use the younger larval stages to initiate queens, yet the addition of young larvae to colonies suppresses queen rearing. One explanation for this phenomenon is that workers receive two signals to inhibit queen rearing, one from QMP and a second from young brood. Pettis and his coauthors have proposed that the queen signal is more important in mediating queen rearing associated with queen loss and swarming, whereas a decline in the brood signal may initiate queen supersedure. Again, however, this brood-queen interaction remains largely unexamined.

\section{PHEROMONE DISPERSAL AND WORKER CONGESTION}

One of the most interesting aspects of honey bee queen pheromone is that it does not prevent queen rearing prior to swarm- ing, in spite of the queen's presence in the colony. Two hypotheses have developed to explain this paradox: 1) queen pheromone production declines prior to swarming, and 2) colony crowding interferes with the movement of queen substances through the nest. The queen production hypothesis appears unlikely, at least as far as QMP is concerned, since the level of QMP produced by pre-swarming queens is identical to the level found in non-swarming queens (Seeley and Fell, 1981).

Recently, we provided evidence that queen pheromone dispersal does change in colonies that are beginning to become crowded with adult workers (Naumann et al., 1993). We tracked the movement of tritiated 9-ODA contained in QMP in crowded versus uncrowded colonies, and found that about $90 \%$ of uncrowded workers had detectable amounts of QMP radiolabel, whereas only about $45 \%$ of workers in crowded colonies showed detectable quantities.

However, population size and congestion did not appear to have an effect on the relative rates of movement from the center to the periphery of the nest. That is, congestion did not change the pattern of pheromone distribution; workers that had received pheromone had similar amounts on their bodies in both crowded and uncrowded situations, and showed similar distribution patterns within the nest. Rather, the effect of crowding appeared to be in the proportion of workers not encountering pheromone rather than in its distribution. This result suggests that population size rather than congestion is important in diluting worker contacts with queen pheromone, leading to diminished efficacy of the adult queen's inhibitory influence on the rearing of new queens.

This study raised a number of important issues concerning queen influence on worker activities. First, the question of population versus congestion needs to be investigated over a wider range of worker 
populations and degrees of congestion. We only examined a level of crowding characteristic of colonies prior to the commencement of pre-swarming queen rearing. Also, our study tracked the movement of radiolabel in colonies; breakdown of pheromone into non-active components might have influenced our conclusions, and a more definitive resolution of this issue awaits techniques that can track pheromone compounds directly. In addition, the eventual identification of other queen pheromones might reveal a different distribution pattern in nests, and require a new interpretation of the relative significance of population size versus congestion. Finally, queen rearing in pre-swarming colonies also could result from a change in worker response to queen pheromone brought on by other factors, such as season, congestion, or others. All of these issues remain unresolved, but are important to understand the biological basis of swarming and to develop management techniques by which swarming might be delayed or prevented.

\section{COMMERCIAL APPLICATIONS OF HONEY BEE PHEROMONES FOR BEEKEEPING AND CROP POLLINATION}

A final research area that begs attention is the application of honey bee pheromones for beekeeping and crop pollination. The broad body of fundamental knowledge concerning queen pheromone has led to a number of recent management applications. QMP has been formulated under the trade names 'Bee Boost' for beekeeping use and 'Fruit Boost' as an attractant for crop pollination, and both products are being used commercially for these applications. For example, 'Bee Boost' has proven effective at enhancing mating success and queen survival in commercial queen rearing operations and as a substitute for queen bees in shipping bulk pack- ages of worker bees long distances (Naumann et al., 1990; Pettis et al., 1993; Winston and Slessor, 1993). 'Fruit Boost' is being sold as a honey bee attractant for use on highbush blueberries, pears, some apple varieties and kiwifruit, and can enhance fruit size and yield significantly enough to increase grower income $\$ 1000$ to $\$ 4000$ US per acre (Currie et al., 1992 a, b; Winston and Slessor, 1993; Naumann et al., 1994).

It is only within the last 10 years that honey bee synthetic pheromones have been sold commercially, primarily as worker attractants to catch swarms (Schmidt et al., 1993; Winston et al., 1993) and pollinate crops (Currie et al., 1992a, b; Naumann et al., 1994; Winston and Slessor, 1993). Pheromone sales for these functions have reached economically noticeable levels, but there is considerable potential for significant expansion in the use of pheromones for these and other purposes.

For example, the addition of synthetic QMP to colonies can prevent swarming for up to 2 months (Winston et al., 1991), providing a potential swarm control technique that could cost as little as $\$ 3$ US annually per colony. However, beekeepers need an appropriate release device that would dispense the proper daily pheromone dose over a 1-2 month period in order to take advantage of QMP's swarm-preventing properties. This type of research is challenging because any release device must not only have the proper biological effect, but its purchase price must be inexpensive enough to make it a viable product. The impact of a successful swarm control technique could have real utility for honey bee management, but success in this area will require a strong interaction between private industry with expertise in pheromone release systems and bee biologists and chemists.

There are numerous other areas where pheromone research might result in com- 
mercial applications. We have barely begun to explore the wide variety of crops that might benefit from attractant sprays that enhance pollination, as well as modes of application or formulations that would improve the efficacy of pheromone attractants. Both worker Nasanov pheromone (formulated and sold under the label 'Bee Scent') and QMP ('Fruit Boost') have been used separately in commercially available attractant products, but to date no one has tested the two pheromones used together as an attractant for pollination. Queen or other pheromones applied within the colony could benefit beekeepers by increasing pollen and/or honey production, but application methods, dosages, blend composition and the colony conditions under which pheromones would be beneficial remain as areas for future work.

Finally, 'Fruit Boost' works within a very narrow dosage range (Currie et al., $1992 \mathrm{a}, \mathrm{b}$ ) outside the hive, without a demonstrable dose-dependent response. In contrast, within-hive functions such as queen rearing exhibit the expected dosedependent response over a wide dosage range (Winston et al., 1989, 1990, 1991), yet unusually high concentrations of QMP have no effect on unrelated worker behaviours (Pettis et al., 1995b). A complete assessment of dose-response relationships and thresholds for various behaviours might be a fruitful area of research for sensory physiologists interested in behaviour to consider.

\section{CONCLUSIONS}

We have attempted in this article to describe some of the challenges remaining in the field of primer pheromone biology, especially with queen pheromones but also with primer pheromones produced by brood and adult worker bees. To date, we know the identity of only one queen pheromone, while other queen substances as well as brood and worker pheromones remain unknown. We know a considerable amount about the functions in which these pheromones are active, but the modes of action, physiological effects and precise chemical nature of specific pheromonal activities remain as subjects for future research. There clearly are commercially useful applications for research in these areas, but our basic knowledge concerning honey bee pheromones will need to expand dramatically to take full advantage of these substances for beekeeping and crop pollination.

Our experience in pheromone research has led us to one final conclusion that may appear obvious, but is worth emphasizing nonetheless. This type of work is truly interdisciplinary, and requires a strong and mutually supportive interaction between honey bee biologists and semiochemists. Progress in our understanding of the role pheromones play in colony organization, and the commercial applications of this knowledge, are not possible without a true meeting of the biological and chemical fields. Science has always progressed by taking new approaches to problems based on interdisciplinary interactions, and the future of pheromone research will be a strong and fascinating one only if we bring to bear the diverse approaches that can come from crossing disciplinary boundaries.

\section{ACKNOWLEDGMENTS}

We gratefully acknowledge the contributions of the numerous undergraduate and graduate students, postdoctoral fellows, technicians and colleagues who have participated in our research program. Heather Higo read the manuscript and provided useful comments. We also deeply appreciate financial support provided by grants from the Natural Sciences and Engineering Research Council of Canada, the Science Council of British Columbia, the British Columbia Ministry of Agriculture, Fisheries, and Foods, the British Columbia Honey 
Producers Association, the Canadian Honey Council, and Phero Tech Inc.

\section{Résumé - Les phéromones modifica- trices et l'organisation de la colonie : lacunes dans nos connaissances. Le but} de cet article est de discuter les lacunes dans nos connaissances sur la façon dont les phéromones modificatrices influent sur les activités des ouvrières et les fonctions de la colonie d'abeilles (Apis mellifera L.). Les phéromones modificatrices, en agissant sur la physiologie des ouvrières, exercent une influence sur la reproduction des ouvrières et de la colonie, sur la structure des castes et sur la division du travail. L'abeille est pourtant le seul insecte social chez lequel une phéromone modificatrice ait jamais été identifiée chimiquement ; il s'agit de la phéromone de la glande mandibulaire de la reine (QMP). Nous décrivons d'abord sa structure chimique et ses fonctions, puis soulignons les domaines qui présentent un intérêt potentiel pour les recherches à venir. Nous discutons le mode d'action de la QMP sur les ouvrières et examinons le rôle de l'HJ comme médiateur de l'action de la QMP. Nous abordons ensuite la question de savoir pourquoi la QMP est un mélange complexe de cinq composés. Pour expliquer la complexité de cette phéromone chez le genre Apis nous proposons un chemin évolutif qui suggère que le nombre accru de composés et les différences entre les reines vierges et les reines fécondes sont des caractéristiques dérivées. Nous discutons les différences biochimiques entre les glandes mandibulaires des ouvrières et celles des reines. Nous présentons ensuite les preuves de l'existence de phéromones royales autres que la QMP et démontrons l'existence d'un autre complexe phéromonal sécrété par des glandes non encore identifiées dans la tête des reines. Nous étudions aussi la façon dont interagissent la phéromone royale et la phéromone de couvain pour influer sur la biologie de la colonie et discutons l'importance relative de la congestion de la colonie et de la taille de la population dans la transmission de la phéromone. Enfin, nous suggérons quelques pistes de recherches susceptibles de donner lieu à des applications commerciales des phéromones d'abeilles pour l'apiculture et la pollinisation des cultures. (c) Inra/DIB/AGIB/Elsevier, Paris

\section{Apis mellifera / phéromone modifica- trice / pheromone royale / intégration colonie}

\section{Zusammenfassung - Primerpheromone und Kolonieintegration bei Honigbie-} nen: Lücken in unserer Kenntnis. In diesem Beitrag sollen Lücken unseres Kenntnisstandes über die Funktion von Primerpheromonen in der Vermittlung zwischen den Aktivitäten der Arbeiterinnen und den Funktionen des Bienenvolkes diskutiert werden. Primerpheromone wirken auf die Physiologie der Arbeiterinnen ein und beeinflussen hierdurch mittelbar die Reproduktion der Arbeiterinnen und des Bienenvolks, die Struktur der Kasten und die Arbeitsteilung. Honigbienen sind die einzigen sozialen Insekten, für die jemals ein Primerpheromon chemisch identifiziert wurde. Dies ist das Pheromon der Mandibeldrüsen der Königin (QMP). Wir beschreiben zunächst die chemische Struktur und die Funktionen des QMP und stellen danach heraus, welche Gebiete von möglicher Bedeutung für zukünftige Untersuchungen sind. Wir diskutieren, auf welche Weise QMP auf die Arbeiterinnen einwirken könnte untersuchen die mögliche Rolle von Juvenilhormon als Aktionsvermittler von QMP. Danach gehen wir auf die Frage ein, warum QMP eine komplizierte Mischung aus fünf verschiedenen chemischen Komponenten ist. Hierbei schlagen wir einen möglichen Evolutionspfad zur Entwicklung der Pheromonkomplexität bei der Gattung 
Apis vor, bei welchem die erhöhte Zahl von QMP-Komponenten und deren Unterschiede bei unverpaarten und verpaarten Königinnen als abgeleitete Eigenschaften gesehen werden. Zum Schluss diskutieren wir die biochemischen Unterschiede zwischen den Mandibeldrüsensekreten von Arbeiterinnen und Königinnen.

In der Folge stellen wir Belege für die Existenz weiterer Königinnenpheromone neben QMP zusammen: Wir legen Resultate vor, die die Existenz eines weiteren Pheromonkomplexes aufzeigen, der von bislang nicht identifizierten Kopfdrüsen der Königinnen ausgeschieden wird. Wir untersuchen weiter, wie Königinnenpheromone und Brutpheromone in ihrem Einfluss auf die Biologie des Bienenvolkes interagieren, und diskutieren die relative Wichtigkeit von Dichte des Bienenbesatzes und Populationsgröße bei der Übertragung der Pheromone. Zum Ende schlagen wir einige Untersuchungen vor, die für die kommerzielle Anwendungen von Honigbienenpheromonen für die Bienenhaltung und die Bestäubung von Bedeutung sein könnten. (C) Inra/DIB/AGIB/ Elsevier, Paris

\section{Apis mellifera / Primerpheromone /Königinnenpheromone / Integration des Bienenvolkes}

\section{REFERENCES}

Allan SD, Slessor KN, Winston ML, King GGS (1987) The influence of age and task specialization on the production and perception of honey bee pheromones. $J$ Insect Phyisiol 33, 917-922

Barbier J, Lederer E (1960) Structure chimique de la « substance royale» de la reine d'abeille (Apis mellifera). CR Séances Acad Sci (Paris) 251, $1131-1135$

Butler CG. Fairey EM (1964) Pheromones of the honcy bec: biological studics of the mandibular gland secretion of the queen. J Apic Res 3, 65-76

Callow RK, Johnston NC (1960) The chemical constitution and synthesis of queen substances of honey bees (Apis mellifera). Bee World 41 . $152-153$
Callow RK, Chapman JR, Paton PN (1964) Pheromones of the honey bee: chemical studies of the mandibular gland secretion of the queen. $J$ Apic Res 3, 77-89

Currie RW, Winston ML, Slessor KN (1992a) Impact of synthetic queen mandibular pheromone sprays on honey bee (Apis mellifera L.) pollination of berry crops. J Econ Entomol 85. 1300-1306

Currie RW, Winston ML, Slessor KN, Mayer DF (1992b) Impact of synthetic queen mandibular pheromone sprays on honey bee (Apis mellifera L.) pollination of liuit crops. J Econ Entomol 85. 1293-1299

Espelie KE, Butz VM, Dietz A (1990) Decyl decanoate: A major component of the tergite glands of honeybee queens, (Apis mellifera $\mathrm{L}$.). $J$ Apic Res 3, 15-19

Fahrbach SE, Giray T, Robinson GE (1995) Volume changes in the mushroom bodies of adult honey bee queens. Ne'urobiology of Learning and Memory 63, 181-191

Fluri P, Sabatini AG, Vecchi MA, Wille H (1981) Blood juvenile hormone, protein and vitellogenin titres in laying and non-laying queen honeybees. $J$ Apic Res 20, 221-225

Free JB (1987) Pheromones of Social Bees. Ithaca, Cornell Univ Press, NY

Gary NE (1961) Queen honey bee attractiveness as related to mandibular gland secretion. Science $133,1479-1480$

Higo HA, Colley SJ, Winston ML, Slessor KN (1992) Effects of honey bee (Apis mellifera $\mathrm{L}$.) queen mandibular gland pheromone on foraging and brood rearing. $C$ an Entomol 124, 409-418

Huang Z-H, Robinson GE (1992) Colony integration in honeybees: worker-worker interactions mediate plasticity in hormonally regulated division of labor. Proc Natl Acad Sci (USA) 89 , $11726-11729$

Jay SC (1970) The effect of various combinations of immature queen and worker bees on the ovary development of worker honeybees in colonies with and without queens. Can J Zool 48, 169-173

Jay SC (1972) Ovary development of worker honeybees when separated from worker brood by various methods. Can I Zool 50, 661-664

Kaatz H-H. Hildebrandt H, Engels W (1992a) Primer effect of queen pheromone on juvenile hormone biosynthesis in adult worker honey bees. $J$ Comp Physiol B 162, 588-592

Kaatz H-H, Engels W, Fischer LC, Hildebrandt $H$ (1992b) Pheromonal control of oogenesis in worker honey bees. In: Adrances in Regulation of Insect Reproduction (B Bennettova, I Gelbic, T Soldan, eds). Crech Acad Sci

Kaminski LA, Slessor KN, Winston ML, Hay NW, Borden JH (1990) Honey bee response to queen mandibular pheromone in laboratory bioassays. J Che'm Ecol 16,84I-850 
Keller L, Nonacs P (1993) The role of queen pheromones in social insects: Queen control or queen signal? Anim Behav 45, 787-794

LeConte Y, Arnold G, Trouiller J, Masson C (1990) Identification of a brood pheromone in honeybees. Naturwissenchaften 77, 334-336

LeConte Y, Sreng L, Poitout SH (1995) Brood pheromone can modulate the feeding behavior of Apis mellifera workers (Hymenoptera: Apidae). J Econ Entomol 88, 798-804

Lensky Y, Slabezki YJ (1981) The inhibitory effect of the queen bee (Apis mellifera L.) footprint pheromone on the construction of swarming cups. J Insect Physiol 27, 313-323

Melathopolous AP, Winston ML, Pettis JS, Pankiw $T$ (1996) Effect of queen mandibular pheromone on initiation and maintenance of queen cells in the honey bee (Apis mellifera L.). Can Entomol 128 263-272

Mohammedi A, Crauser D, Paris A, LeConte Y (1996). Effect of a brood pheromone on honeybee hypopharyngeal glands. CR Acad Sci Paris, Sciences de la vie, 769-772

Moritz RFA, Crewe RM (1988) Chemical signals of queens in kin recognition of honeybees, Apis mellifera L. J Comp Physiol A 164, 83-89

Moritz RFA, Crewe RM (1991) The volatile emissions of honeybee queens. (Apis mellifera L.) Apidologie 22, 205-212

Naumann K (1991) Grooming behaviors and the translocation of queen mandibular gland pheromone on worker honey bees. Apidologie $22,523-531$

Naumann K, Winston ML, Wyborn MH, Slessor KN (1990) Effects of synthetic honey bee (Hymenoptera: Apidae) queen mandibular gland pheromone on workers in packages. $J$ Econ Entomol 83, 1271-1275

Naumann K, Winston ML, Slessor KN, Prestwich GD, Webster FX (1991) The production and transmission of honey bee queen (Apis mellifera L.) mandibular gland pheromone. Behav Ecol Sociobiol 29, 321-332

Naumann K, Winston ML, Slessor KN, Prestwich GD, Latli B (1992) Intra-nest transmission of aromatic honey bee queen mandibular gland pheromone components: movement as a unit. Can Entomol 124, 917-934

Naumann K, Winston ML, Slessor KN (1993) Movement of honey bee (Apis mellifera L.) queen mandibular gland pheromone in populous and unpopulous colonies. J Insect Behav 6, 211-223

Naumann K, Winston ML, Slessor KN, Smirle MJ (1994) Synthetic honey bee (Hymenoptera: Apidae) queen mandibular gland pheromone applications affect pear and sweet cherry pollination. J Econ Entomol 87, 1565-1599

Pankiw T (1997) Queen attendance behaviour of worker bees that are high and low responding to queen mandibular pheromone. Can Entomol (in press)

Pankiw T, Winston ML, Slessor KN (1994) Variation in worker response to honey bee (Apis mellifera L.) queen mandibular pheromone. IInsect Behav $7,1-15$

Pankiw T, Winston ML, Slessor KN (1995) Queen attendance behavior of worker honey bees (Apis mellifera $\mathrm{L}$.) that are high and low responding to queen mandibular pheromone. Insectes Soc 41, 371-378

Pankiw T, Winston ML, Plettner E, Slessor KN, Pettis JS, Taylor OR (1996) Mandibular gland components of European and Africanized honey bee queens (Apis mellifera L.). J Chem Ecol 22, $605-615$

Pankiw T, Huang Z-Y, Winston ML, Robinson GE (1998). Queen mandibular gland pheromone influences worker honey bee (Apis mellifera L.) juvenile hormone titers and foraging ontogeny. $J$ Insect Physiol (in press)

Pettis JS, Winston ML, Malyon M, Slessor KN (1993) The use of honey bee queen mandibular gland pheromone ( «Bee Boost») in mating nuclei management. Am Bee $J$ 133, 725-727

Pettis JS, Winston ML, Collins AM (1995a) Suppression of queen rearing in European and Africanized honey bees Apis mellifera L. by synthetic queen mandibular gland pheromone. Insectes Soc 42, 113-121

Pettis JS, Winston ML, Slessor KN (1995b) Behavior of queen and worker honey bees Apis mellifera L. (Hymenoptera: Apidae) in response to exogenous queen mandibular gland pheromone. Insectes Soc 42. 371-378

Pettis JS, Higo HA, Pankiw T, Winston ML (1997) A queen rearing suppression in the honey bee evidence for a fecundity signal. Insectes Soc 44 , $311-322$

Plettner E, Slessor KN, Winston ML, Robinson GE, Page RE (1993) Mandibular gland components and ovarian development as measures of caste differentiation in the honey bee (Apis mellifera L.). J Insect Phrsiol 39, 235-240

Plettner E, Slessor KN, Winston ML, Oliver JE (1996) Caste-selective pheromone biosynthesis in honeybees. Science 271, 1851-1853

Plettner E, Otis GW, Wimalaratne PDC, Winston ML, Slessor KN, Pankiw T, Punchihewa PWK (1997) Species- and caste-determined mandibular gland signals in honey bees (Apis). $J$ Chem Ecol 23, 363-377

Ratnieks F (1995) Evidence for a queen-produced egg-marking pheromone and its use in worker policing in the honey bee. J Apic Res 34, 31-37

Renner M, Baumann M (1964) Über Komplexe von subepidermalen Drüsenzellen (Druftdrüsen) der Bienenkönigin. Natumwissenschaften 51, 68-69 
Robinson GE (1992) Regulation of division of labor in insect societies. Annu Rev Entomol 37, 637-665

Robinson GE, Strambi C, Strambi A, Feldlaufer MF ( 1992) Comparison of juvenile hormone and ecdysteroid haemolymph titres in adult honey bee workers and queens. J Insect Physiol 37, 929-935

Sasaki M, Irokawa T, Sato M (1989) Humoral control of the queen pheromone (9ODA) biosynthesis in honeybees: Induction in queenless workers and in worker mandibular gland implanted into the queen. Bull Fac Agr, Tamagawa Univ 29, 11-21

Schmidt JO, Slessor KN, Winston ML (1993) Roles of Nasanov and queen pheromones in attraction of honeybee swarms. Naturwissenschaften 80 , $573-575$

Seeley TD (1979) Queen substance dispersal by messenger workers in honeybee colonies. Behav Ecol Sociobiol 5, 391-415

Seeley TD, Fell RD (1981) Queen substance production in honey bee (Apis mellifera) colonies preparing to swarm (Hymenoptera: Apidae). $J$ Kans Entomol Soc 54, 192-196

Slessor KN, Kaminski L-A, King GGS, Borden JH, Winston ML (1988) Semiochemical basis of the retinue response to queen honey bees. Nature $332,354-356$

Slessor KN, Kaminski L-A, King GGS, Winston ML (1990) Semiochemicals of the honey bee queen mandibular glands. J Chem Ecol 16 , $851-860$

Slessor KN, Foster LJ, Winston ML (1997) Royal flavours: Honey bee queen pheromones. In: Pheromones of Social Insects (R Vandermeer, M Breed, K Espelie, M Winston, eds), Westview Press, Boulder, CO (in press)

Smith DR (1991) Diversity in the Genus Apis. Westview Press, Boulder, CO

Smith R-K, Spivak M, Taylor OR, Bennett C, Smith ML (1993) Maturation of tergal gland alkene profiles in European honey bee queens Apis mellifera L. J Chem Ecol 19, 133-142

Velthuis HHW (1967) On abdominal pheromones: the queen honeybee. Proc 21 st Int Beekeeping Congress, College, Maryland, USA, p 472

Velthuis HHW (1970) Queen substance from the abdomen of the honeybee queen. $Z$ vergl Physiol $70,210-222$

Vierling G, Renner M (1977) Die Bedeutung des Sekretes der Tergittaschendrüsen für die Attrak- tivität der Bienenkönigin gegenüber jungen Arbeiterinnen. Behav Ecol Sociobiol 2, 185-200

Watmough J (1996) The dynamics and structure of groups: two case studies of the common honey bee. PhD dissertation, Univ British Columbia, Vancouver, BC Canada

Willis LG, Winston ML, Slessor KN (1990) The effect of queen honey bee (Hymenoptera: Apidae) mandibular pheromone on worker ovary development. Can Entomol 122, 1093-1099

Winston ML (1987) The Biology of the Honey Bee. Harvard Univ Press, Cambridge, MA

Winston ML (1992) Semiochemicals and insect sociality. In: Evolutionary Perspectives on Insect Chemical Ecology (M Isman, B Roitberg, eds), Chapman and Hall, NY

Winston ML, Slessor KN (1992) An essence of royalty: honey bee queen pheromone. Am Sci 80 , 374-385

Winston ML, Slessor KN (1993) Applications of queen honey bee mandibular pheromone for beekeeping and crop pollination. Bee World 74 , $111-128$

Winston ML, Taylor OR (1980) Factors preceding queen rearing in the Africanized honeybee (Apis mellifera) in South America. Insectes Soc 27, 289-304

Winston ML, Slessor KN, Smirle MJ, Kandil AA (1982) The influence of a queen-produced substance, 9HDA, on swarm clustering behavior in the honeybee Apis mellifera L. J Chem Ecol 8, 1283-1288

Winston ML, Slessor KN, Willis LG, Naumann K, Higo HA, Wyborn MH, Kaminski L-A (1989) The influence of queen mandibular pheromones on worker attraction to swarm clusters and inhibition of queen rearing in the honey bee (Apis melliferal L.). Insectes Soc 36, 15-27

Winston ML, Higo HA, Slessor KN (1990) The effect of various dosages of queen mandibular pheromone on the inhibition of queen rearing in the honey bee (Hymenoptera: Apidae). Ann Entomol Soc Am 83, 234-238

Winston ML, Higo HA, Colley SJ, Pankiw T, Slessor $\mathrm{KN}$ (1991) The role of queen mandibular pheromone and colony congestion in honey bee (Apis mellifera L.) reproductive swarming. $J$ Insect Behav 4, 649-660

Winston ML, Slessor KN, Rubink WL, Villa JD (1993) Enhanced pheromone lures to attract honey bee swarms. Am Bee J 133, 58-60 